Methodological Approach for Reducing Computational Costs of Vehicle Frontal Crashworthiness Analysis by Using Simplified Structural Modelling

Michael Schäffer

Institute of Vehicle Concepts, German Aerospace Center (DLR), Germany

Michael.Schaeffer@DLR.de

Ralf Sturm

Institute of Vehicle Concepts, German Aerospace Center (DLR), Germany

Horst E. Friedrich

Institute of Vehicle Concepts, German Aerospace Center (DLR), Germany 


\title{
Methodological Approach for Reducing Computational Costs of Vehicle Frontal Crashworthiness Analysis by Using Simplified Structural Modelling
}

\begin{abstract}
A challenge in the design and optimisation of the vehicle front structures is the high computational costs required for crash analysis. A methodological approach to simplifying Finite Element (FE) vehicle models and crash barriers is presented in this paper. The methodology uses global deformation characteristics of structures which are obtained from the global crash model. For the simplification of the vehicle crash model, structural regions which sustain only elastic deformations during the frontal crash are replaced by kinematic numerical representations which describe both stiffness and load paths at the interface of the substituted structures. Verification studies of the simplified vehicle model show a very good agreement of the global and local structural response during the frontal crash. Further simplifications were applied to the offset deformable barrier (ODB) by replacing its detailed crushing behaviour by kinematic descriptions. Through the combined use of both simplified numerical representations, the computational cost of a Euro NCAP offset crash analysis can be reduced by around $92 \%$. With the obtained time reduction, structural optimisation studies of the remaining structure can be conducted efficiently for the identification of weight reduction potentials.
\end{abstract}

\section{Keywords}

Crashworthiness, Physical Surrogates, Simplified models, Multi-body system approach, Optimisation

\section{Introduction}

Climate change caused by greenhouse gases (mainly $\mathrm{CO}_{2}$ ) and the increasing scarcity of energy and material resources can be identified as reasons for the establishment of international restrictions on the energy consumption of vehicles. These force car manufacturers to design ever more energy efficient vehicle concepts, e.g. [26].

Lightweight design has therefore become more important in vehicle development, as a way to increase the energy efficiency of the automotive body-in-white. The objective of lightweight design is to meet the requirements that legislators and customers have set for vehicles (e.g. vehicle safety, driving comfort, fuel consumption, costs) at minimal mass. It has been shown that up to $1 / 3$ of the total energy consumption of vehicles is mass-dependent [19]. Thus, a low vehicle mass is an essential factor to reduce the energy consumption of a car.

The challenging objectives of ensuring lightweight construction and crash safety are supported significantly by simulation methods and structural optimisation procedures. It is imperative to systematically incorporate these methods and procedures into the product development process, even in light of ever shorter product life cycles, which have been more than halved [7], [17].

By the application of structural optimisation studies, the structural mass and the development time of the vehicle body can be reduced.

However, currently optimisation of crash load cases cannot be carried out with a full vehicle model due to the long computational time required per simulation. In [18] the influence of the crash load case on the computational time is shown.

In the case of full vehicle optimisation, the time required to obtain the optimisation results can quickly increase to several weeks [7]. To counteract this, various countermeasures are described, 
such as increasing the number of CPUs or selecting a better optimisation algorithm. Another option for reducing the computational time is through the use of surrogate models [30].

But it is not only the use of a full vehicle model that increases computational times; the modelling of the respective deformable impactors also plays a noteworthy role, depending on the load case. As shown in [31], the modelling of a deformable barrier also significantly influences the computational time.

Efforts are taken to reduce the computational time and concurrently the optimisation time using surrogate models. Fundamental measures are to simplify FE vehicle models, such as increasing the time step (e.g. mass scaling), changing element type and element size and element deletion (e.g. removal of door panels) [30], [2] and [29].

The influence of mesh size and mesh orientation on the deformation behaviour of a structure under axial load and on computational time is demonstrated in [12]. In [30] it is shown that by increasing the time step, changing the element type and modifying the contacts, a $25 \%$ gain in computational time compared to that of a full vehicle model could be obtained.

According to [8], physical surrogate models can be subdivided into eight approaches, each of which represents a part of the physical behaviour. The most important simplification methods for vehicle crash models are the hybrid nonlinear FE-rigid approach, the beam approach, the sub-structure modelling approach and the multi-body system approach.

In [11] the number of elements in an FE vehicle model is reduced by removing the rear structure of the vehicle behind the B-pillar and replacing the masses and inertial properties of the removed components with a rigid body. The rigid body is connected using the vehicle's load-bearing structures. In this way, the crash kinematics of the full vehicle are modelled; however, direct application of the masses and inertial properties of the crash model to the rigid body description is not possible, as a different deformation behaviour of the body structure is obtained. A correct deformation behaviour is only obtained after adapting the mass and the inertial properties of the rigid body [11]. For the structural optimisation of a crash box, in [29] the full vehicle crash model is reduced by replacing all crash-irrelevant components (e.g. rear structure of body-in-white, doors and interior) with rigid bodies with corresponding mass and inertial properties. Subsequent optimisation of the masses and inertial properties was also necessary to model the deformation behaviour, as the initial deviation of the internal energy in the crash box was $25 \%$ between the full car and the surrogate model. After calibrating the rigid body properties, a $~ 90 \%$ computational time reduction could be achieved with a deviation of $5.4 \%$. Different simplification strategies for a vehicle crash model, from an increase in time step to the hybrid non-linear FE rigid body approach was investigated in [30]. In these studies a reduction in computational cost of up to $73 \%$ could be obtained. The main reduction (up to $61 \%$ ) was achieved using the hybrid non-linear FE rigid body approach; all further simplification strategies had only minor influences.

A combination of macro and detailed FE description for structural optimization of a side crash concept for a battery-electric vehicle was investigated in [28]. In these studies the computational cost was reduced up to $98 \%$ in comparison to the full-vehicle simulation with an accuracy of $2.5 \%$ deviation for intrusion compared to the full-vehicle simulation.

For FE beam models, as described in [27], [15] and [25], the vehicle structures (such as the front section) are represented only as a kinematic description. In this description the deformation characteristics of entire structures are replaced by macro elements. The required characteristics can be determined by means of experiments [4], detailed simulations [28] or analytical correlations [9]. The disadvantage of this approach is the fact that correlation of the stiffness values to the structural concepts is not possible. A kinematic description can also be used to reduce the computational cost for crash barriers [31]. With the simplified barrier, the computational cost of the model could be reduced up to more than 15 times.

A slight disadvantage of the applied simplification approach is the lack of representation of the deformation over the height of the barrier, since a simulation with a full vehicle front section results in different levels of deformation above the barrier. 
In [1] and in [32] the sub-structure modelling approach is used to simplify vehicle models. Computational reduction of original simulation models to a sub-model is obtained by applying kinematic conditions to the interface nodes and by removing structural parts of the vehicle model (in case of a front crash for example the whole rear structure of the vehicle). A disadvantage with this approach is that the extent to which a change in design affects the applied displacement parameters cannot be verified.

The multi-body system approach represents a very simple but effective modelling technique; here, the structural behaviour of the components is represented by mass-spring-damper systems, e.g. [14], [10], [16], [6], [20], [13], [24], [21] and [9]. This modelling method is particularly well suited to parametric studies during the conceptualisation phase within a product development process. The structural properties have to be determined experimentally or adjusted iteratively in order to be able to reproduce the desired structural behaviour. However, the identification of structural parts with the required deformation characteristic can be a significant challenge. Still, the multi-body system approach can be used and expanded to estimate the loads on the vehicle passengers in the early development process [5], [23].

In this paper a new methodological approach is presented for reducing the computational costs of a frontal crash analysis by replacing the elastic structural regions by kinematic numerical representations. Additionally a simplified representation of the ODB barrier is described. Both methods offer a significant computational time reduction potential without the requirement of an iterative calibration procedure.

\section{Methodological Approach}

A vehicle FE crash model of the Toyota Yaris from the National Crash Analysis Center library was used for this paper. The FE model is based on the structural definitions of a real vehicle and contains 1514068 elements. The FE model was verified and validated by comparing crash test and simulation results for the acceleration and energy absorption of the vehicle [22]. A validation was carried out for a full frontal impact and for an offset deformable barrier crash test. A validated detailed FE barrier model provided by Livermore Software Technology Corp. (LSTC) was used to develop a simplified numerical description of the ODB [3]. All simulations were performed using LS-DYNA version 7.1.2.

\subsection{Simplified Offset Deformable Barrier}

In a crash load case, the ODB represents the front structure of an oncoming vehicle. The barrier consists of two parts: the main block and the stiffer bumper. Both elements are made of aluminium honeycombs. Both parts are covered with an aluminium sheet. For the identification of the individual failure characteristics, each component of the validated detailed LSTC shell barrier [3] was compressed using a rigid block impactor. The FE model of the barrier is based on the structural definition of a real barrier and contains 1504794 elements. For a coarse vehicle FE model the small timestep of the LSTC shell barrier can also influence the overall time step of a crash simulation. Therefore, a simplification method is needed to reduce the cost-intensive barrier modelling. Figures 1 and 2 show the obtained unfiltered force displacement results of the detailed FE model for the bumper and the main block. Based on the results, a simplified force displacement curve was derived, which is also depicted in figure 1 and 2.

Based on these global failure characteristics, a kinematic description of the barrier deformation was developed. Figure 3 shows the FEM model and figure 4 shows a schematic representation of the simplified barrier. By applying the global characteristics to the macro elements, it is possible to model the intrusion behaviour of the vehicle into the barrier. Therefore, simulations of the ODB crash test can be performed requiring significantly less computational time. 


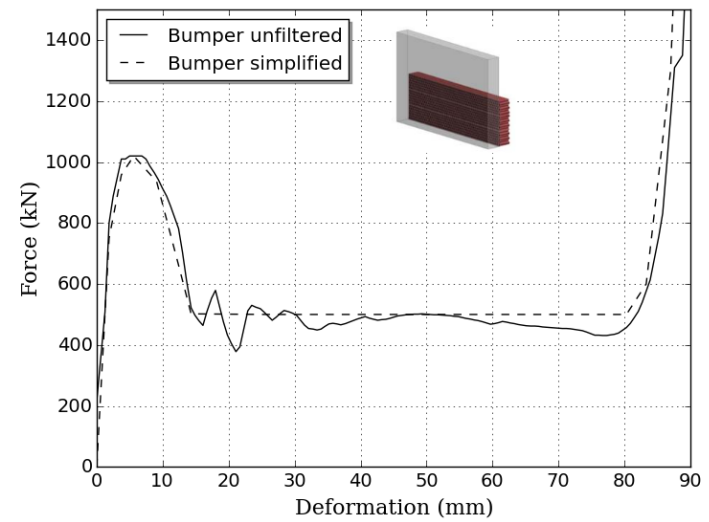

Fig. 1: Force - deformation plot of bumper element of the LSTC shell barrier model

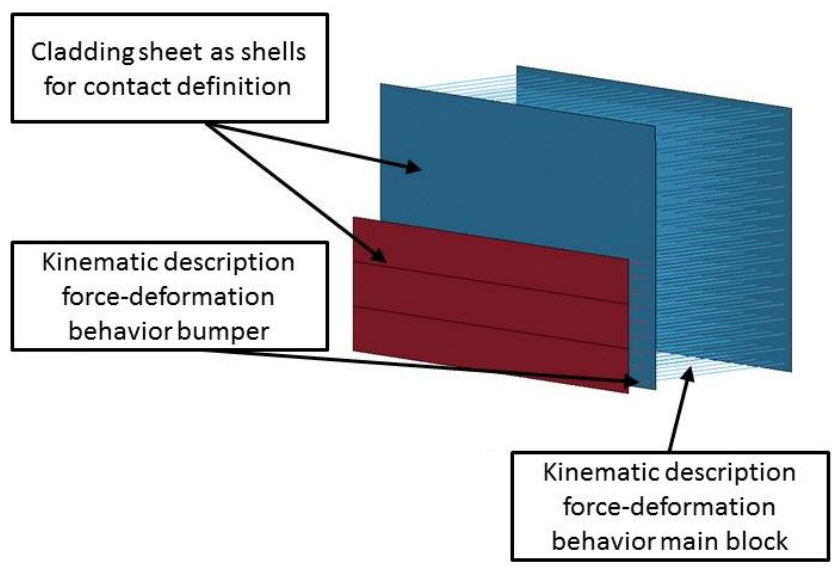

Fig. 3: FEM model of the simplified barrier

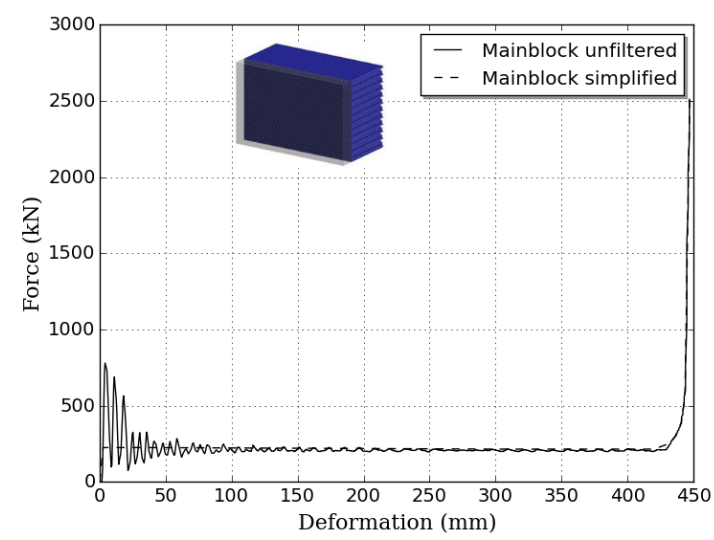

Fig. 2: Force - deformation plot of main block of the LSTC shell barrier model

In the simplified barrier model, shown in figure 4, the main block and bumper are modelled with 720 and 360 non-linear discrete beam elements respectively. The abstracted force/displacement characteristics from figures 1 and 2 are defined for the respective beam elements of the bumper and the main block. At the start of deformation, the beam elements of the bumper have a force peak of approximately $1000 \mathrm{kN}$, after which a force level of approximately $500 \mathrm{kN}$ is retained up to full compaction. The beam elements of the main block experience a constant force level of approximately $230 \mathrm{kN}$ up to compaction. At the rear, the barrier is connected to a rigid wall with fixed boundary conditions, which represents the steel construction in the real test set-up. A simplified shell representation of the deformable cladding sheet is attached between the bumper and main block and at the front of the barrier. These shell elements serve as a contact surface, on the one hand, but also make local intrusions into the simplified barrier possible. All cladding sheet nodes are limited in their movement in such a way that only axial intrusions are possible for the barrier. Lateral movements are completely prevented, as axial buckling and local crushing is the predominant failure behaviour of the aluminium honeycombs of the barrier [3].

The deformation behaviour of the simplified barrier was analysed and verified using two different degrees of overlap. In the first load case, an impactor with a mass of $5000 \mathrm{~kg}$ intrudes with a speed of $64 \mathrm{~km} / \mathrm{h}$ and a $100 \%$ overlap into the barrier. Figure 5 shows the deformation behaviour of the LSTC shell barrier [3] and simplified barrier. This load case is mainly used to adjust the failure behaviour of the beam elements with the failure behaviour of the LSTC shell barrier [3]. The comparison of the force-time characteristic curves in figure 6 between barrier and impactor also shows a good correlation between the two barrier representations. The good agreement is obtained for the initial, almost constant, force level of the main block as well as through the higher force level through deformation of the bumper. 

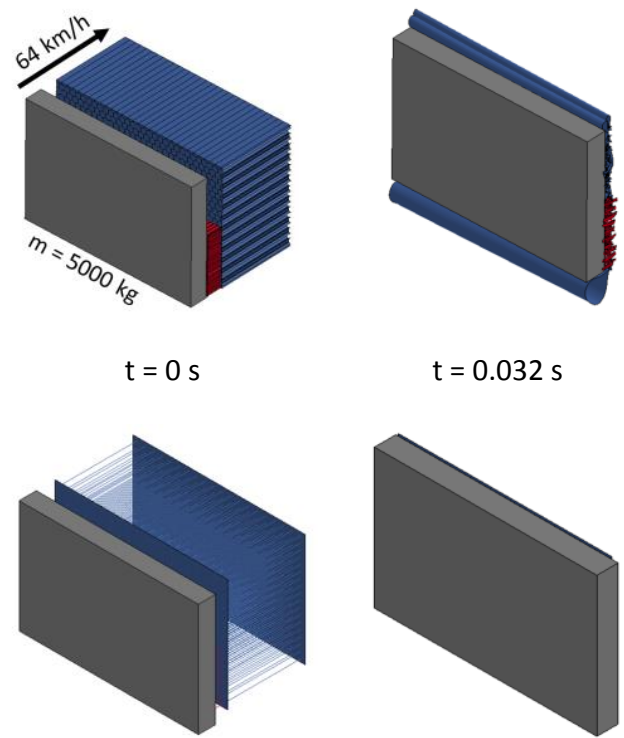

Fig. 5: Comparison of LSTC shell barrier and simplified barrier for a $100 \%$ overlap rigid impactor

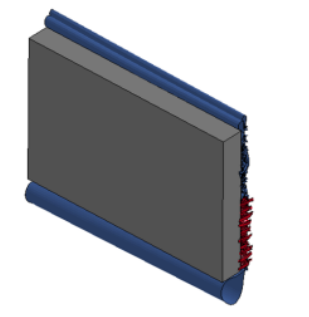

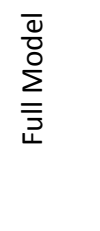

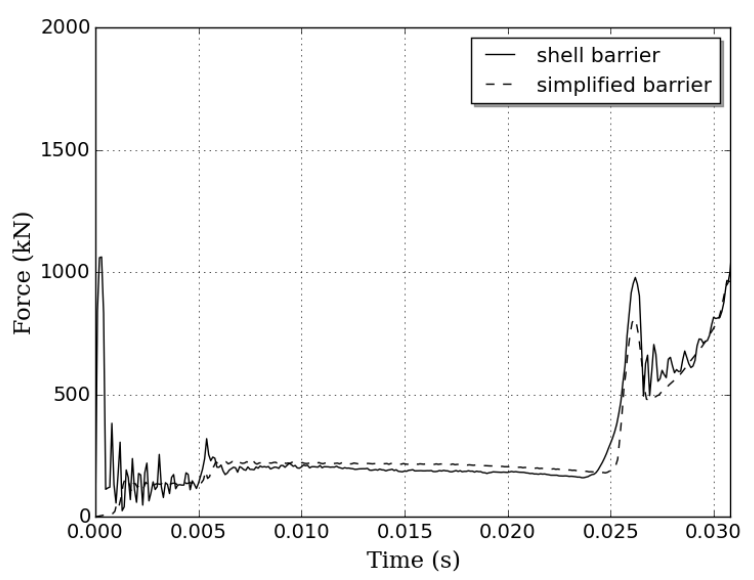

Fig. 6: Force-time plot for compression of a LSTC shell barrier and simplified barrier with a $100 \%$ overlap rigid impactor

As a second verification load case, an intrusion of the impactor with a $40 \%$ overlap was chosen, as this represents a load case that is close to that used for the Euro NCAP ODB crash test. Figure 7 shows a deformation pattern of the bumper and the main block without significant lateral deformation in the case of the LSTC shell barrier. The cladding sheet also has little influence on the deformation behaviour, as these fail and tear under the crash loads. This failure behaviour can also be modelled using the simplified barrier. The material properties of the cladding sheet are defined such that the cladding surface provides a stable contact surface that does not, however, exert any influence on the deformation behaviour of the beam elements. This also becomes clear when considering the force-time characteristic curve - see figure 8 . The constant force level of the main block is effectively represented; only during subsequent compaction of the bumper is the simplified barrier slightly above the force level of the detailed barrier.

A comparison of the basic specifications of the shell and simplified barrier model can be seen in table 1. It shows the reduction in computational time of the developed barrier model. Using the kinematic description of the barrier, the number of elements can be reduced to only $0.13 \%$ of elements of the full barrier, leading to a reduction of computational time from $5 \mathrm{~h} 48 \mathrm{~min}$ to 40 seconds.
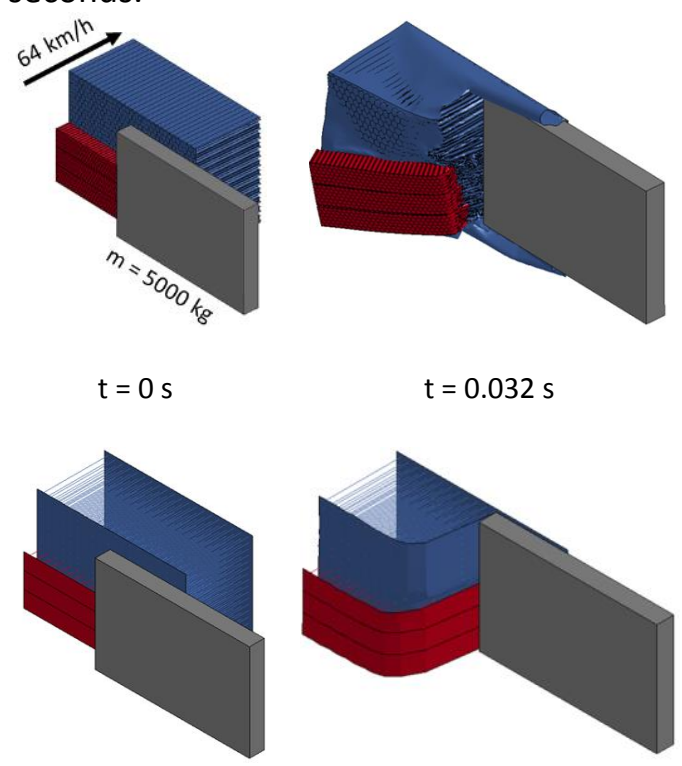

Fig. 7: Comparison of LSTC shell barrier and simplified barrier for a $\mathbf{4 0} \%$ overlap rigid impactor
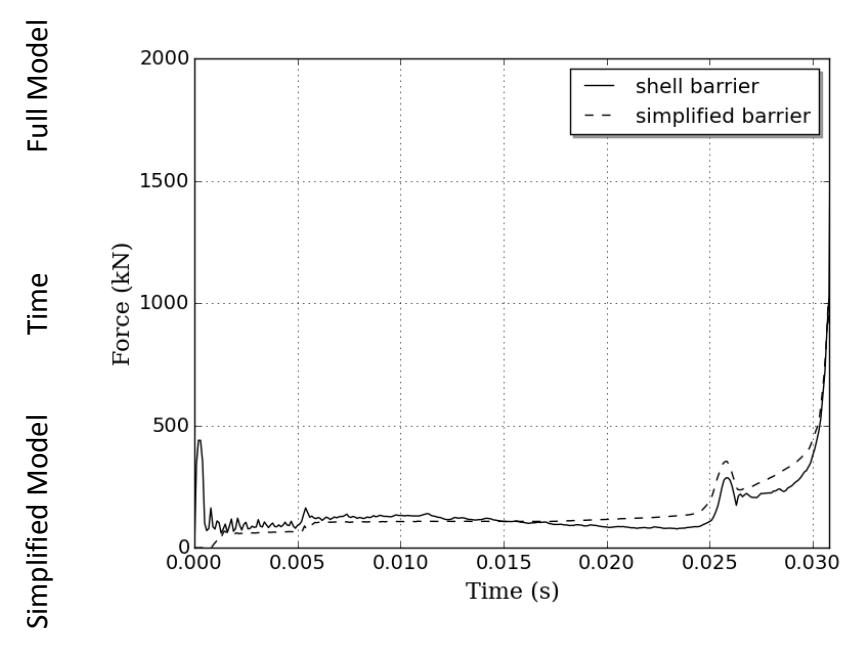

Fig. 8: Force-time plot for compression of a shell barrier and simplified barrier with a $\mathbf{4 0} \%$ overlap rigid impactor 
Table 1: Comparison of shell and simplified barrier model *(Intel Xeon E3-1275 4 CPUs)

\begin{tabular}{lcc}
\hline & LSTC shell barrier & simplified barrier \\
\hline Nodes & 1085806 & 3930 \\
\hline Beam elements & 0 & 1080 \\
\hline Shell elements & 1504794 & 900 \\
\hline Solid elements & 0 & 0 \\
\hline Element sum & 1504794 & 1980 \\
\hline Time step & $4.67 \mathrm{E}-4 \mathrm{~ms}$ & $4.75 \mathrm{E}-2 \mathrm{~ms}$ \\
\hline Computational time* & $5 \mathrm{~h} \mathrm{48} \operatorname{min~} 58 \mathrm{~s}$ & $40 \mathrm{~s}$ \\
\hline
\end{tabular}

\subsection{Simplified Vehicle FE Model}

For a further reduction of computational time, a new four-step approach for the generation of a simplified vehicle model was developed. The four steps are described in figure 9 . The main approach to reduce the computational time of the crash model is the kinematic representation of structural parts which have only elastic deformations during the crash.

Within these four steps, the characteristics to model the global deformation behaviour are determined which are required to generate a simplified description of the vehicle crash model. These characteristics include the mass, centre of gravity of the structure to be replaced, the force pulse distribution in the interface and the stiffness of the replaced body structure in the longitudinal direction. In the following the individual steps are explained, which, in the final step, generate the surrogate vehicle FE crash model.

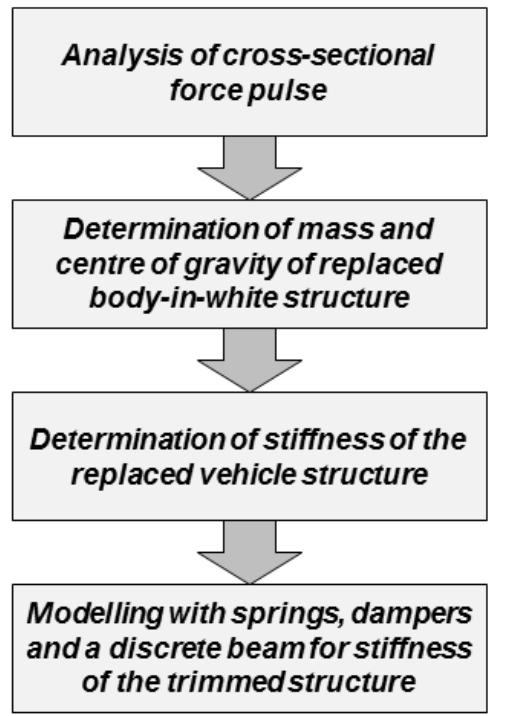

Fig. 9: Four-step approach for simplified FE vehicle model generation

\section{Analysis of Cross-Sectional Force Pulse}

Firstly, the force pulse in the selected interface within the load-bearing structures is analysed, with components grouped into assemblies. In this way, for example, the different sheet-metal components of the door sill, including reinforcement sheets, are combined to form a door sill assembly. In the performed investigation, the car structure was separated into the assemblies Apillar right, A-pillar left, door sill left, door sill right, floor right, floor left, tunnel, exhaust, door left, door right and windshield. 


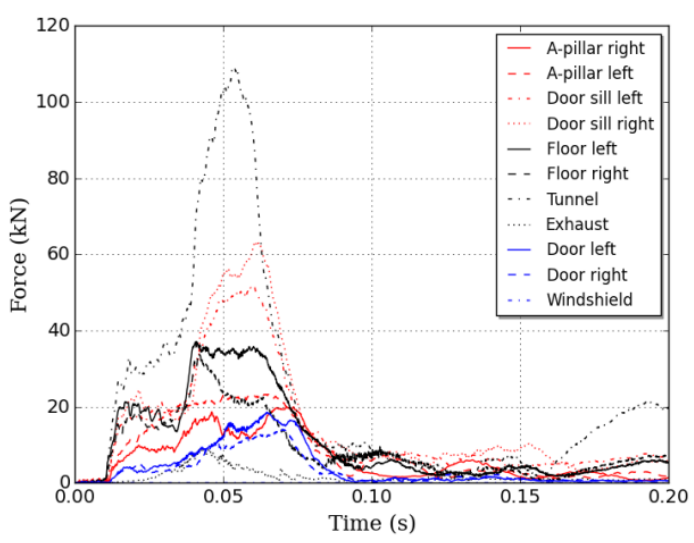

Fig. 10: Force-time curves of defined assembly groups

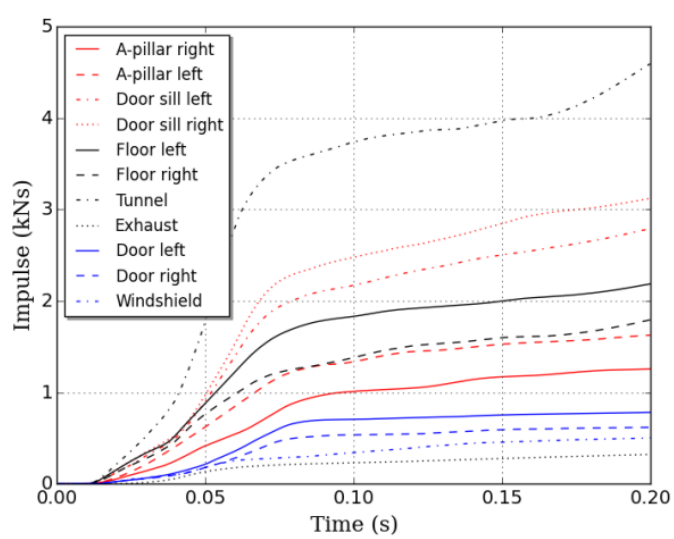

Fig. 11: Impulse-time curves of defined assembly groups

By using different assemblies, the force-time characteristic curves can be determined during the crash load case. In figure 10, the force-time characteristic curves of the eleven assemblies can be seen for the crash load case with $100 \%$ overlap and an impact speed of $56 \mathrm{~km} / \mathrm{h}$. The main load paths for the investigated car can be clearly identified through the tunnel and respective door sill structures. In figure 11, the impulse-time characteristic curves are shown, which were obtained by integration of the force-time characteristic curves. To quantify the load-path distribution, the maximum impulse for all assemblies is taken. Using the impulses the individual load-path distribution can be determined for each investigated crash load case. Figure 12 shows the load-path distributions for the following crash load cases: US NCAP $(100 \%, 56 \mathrm{~km} / \mathrm{h})$ and Euro NCAP $(40 \%, 64 \mathrm{~km} / \mathrm{h})$. For the $100 \%$ and $40 \%$ overlap, it is clear that the most significant load paths are the tunnel and door sill structures. These load-path distribution percentages are required for the subsequent simplified vehicle model generation, since the stiffness of the car body is split into linear kinematic stiffness representations according to the obtained percentage values.

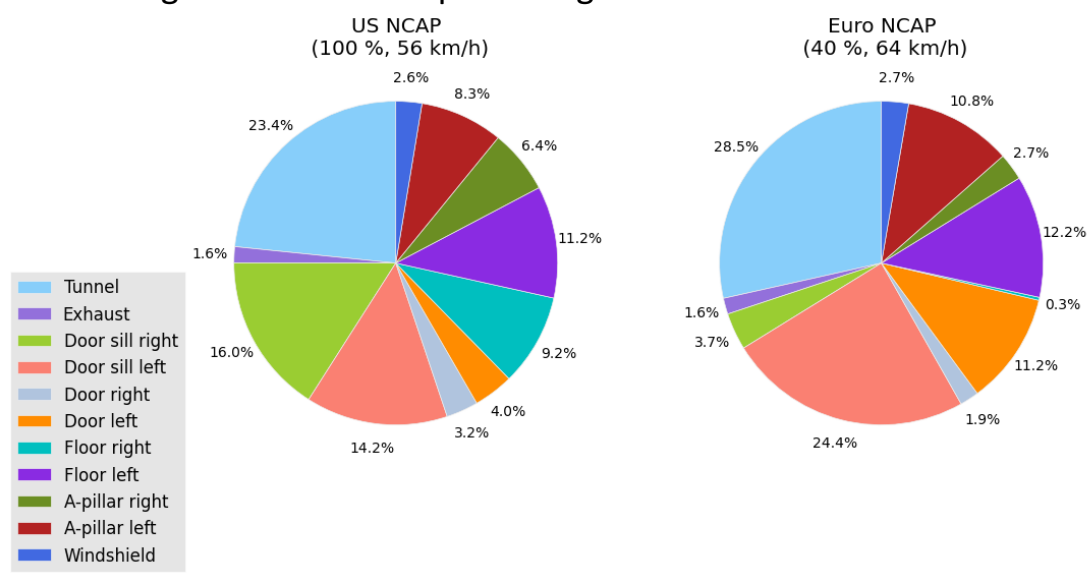

Fig. 12: Distribution of load path in the interface for different crash load cases

\subsection{Analytical Description of the Kinematic Simplifications}

The main aspect of the vehicle simplification methodology is a direct correlation between the stiffness of the local structural subsystems and the impulse distribution obtained during the crash. In figure 13 the applied numeric description is shown schematically. 


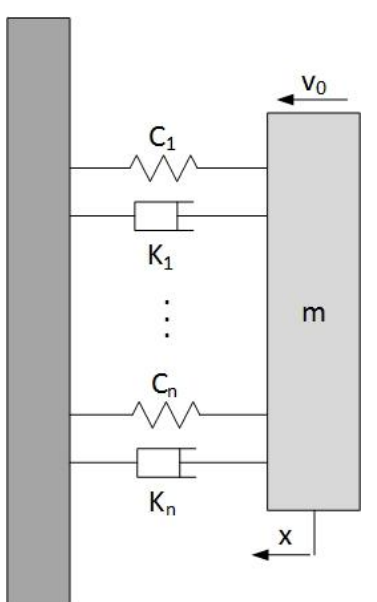

Fig. 13: Applied mass-spring-damper system for the vehicle model simplification

The kinematic system consists of a mass representing the mass of the replaced vehicle structure with a defined kinetic energy, connected via linear spring-damper systems to a mass representing the front structure of the vehicle. The number of spring-damper systems directly depends on the number of different structural assemblies which are used for simplification. Considering the kinematic system, the equation of motion can be described with the Lagrange equation as

$\frac{d}{d t} \frac{\partial E_{k i n}}{\partial q_{l}}-\frac{\partial E_{k i n}}{\partial q_{i}}+\frac{\partial E_{p o t}}{\partial q_{i}}=Q_{i}$

where $q_{i}$ are the generalized coordinates, $Q_{i}$ are the external forces in $q_{i}$ direction, $E_{k i n}$ corresponds to the kinetic energy and $E_{p o t}$ corresponds to the potential energy of the system. Considering the investigated crash load case the initial conditions of the system are

$0 \leq \mathrm{t} \geq \mathrm{T}$

$\mathrm{x}_{(0)}=0$

$\dot{x}_{(0)}=v_{0}$

$\mathrm{Q}=0$

Where $t$ is the time, $v_{0}$ is the initial velocity of the mass. For the kinematic system the kinetic energy $E_{k i n}=1 / 2 m \dot{x}^{2}$ and the potential energy of the spring deformation $E_{p o t}=1 / 2 c x^{2}$ can be applied to equation (1).

Additionally considering the significance of the acceleration loads during a crash loading, an assumption can be made that the damping of the system can be neglected.

$\frac{\partial E_{k i n}}{\partial x}=0$

Applying equation (3) and (2) to equation (1) the equation of motion for the system becomes

$m \ddot{x}-c x=0$

Equation (4) can be integrated over the crash period to obtain the required relation between the system deformation and the crash impulse. Integrating the acceleration term of equation (4) the crash impulse $\mathrm{F}$ is obtained

$m \ddot{x}=m \int \ddot{x} d t=m v-m v_{0}=\int F d t=\vec{F}$ 
Considering a linear elastic element with an initial length $I_{0}$, a stiffness $E$ and an area $A$, the integrated deformation term can be described as

$c x=c \int x d t=\frac{E A}{l_{0}} \int x d t=\frac{E A}{l_{0}}\left(\frac{1}{2} x^{2}\right)$

For small rotations of the interface the spring deformation can be divided into $i$ spring subsystems. For each spring $i$ a direct relationship between the elastic spring deformation and impulse is obtained by applying equation (5) and (6) into equation (4).

$\overrightarrow{F_{l}}=\frac{E_{i} A}{l_{0}}\left(\frac{1}{2} x_{i}^{2}\right)$

Normalizing equation (7) by dividing the impulse $i$ by the global impulse of the system and the stiffness $E_{i}$ by the stiffness of the global system, equation (7) becomes

$\frac{\vec{F}_{l}}{\sum \vec{F}_{l}}=\frac{\frac{E_{i} A}{l_{0}}\left(\frac{1}{2} x_{i}{ }^{2}\right)}{\sum \frac{E_{i} A}{l_{0}}\left(\frac{1}{2} x_{i}^{2}\right)}$

Equation (8) is dependent on the area of the elastic spring elements. After defining a constant area for all elastic spring elements $i$, the relationship can be described as

$\frac{\overrightarrow{F_{l}}}{\sum \overrightarrow{F_{l}}}=\frac{\frac{E_{i} A}{l_{0}}\left(\frac{1}{2} x_{i}{ }^{2}\right)}{\frac{A}{l_{0}} \sum E_{i}\left(\frac{1}{2} x_{i}{ }^{2}\right)}=\frac{E_{i}\left(\frac{1}{2} x_{i}{ }^{2}\right)}{\sum E_{i}\left(\frac{1}{2} x_{i}{ }^{2}\right)}$

Equation (9) shows the required direct correlation between the impulse distribution through the vehicle and the stiffness of beam elements representing the structural assemblies after the interface. With this approach it is possible to directly apply the load distribution obtained in global crash simulation into linear kinematic descriptions of the beam elements at the interface.

\section{Determination of Mass and Centre of Gravity of Replaced Body-in-White Structure}

An important aspect when generating simplified vehicle models is to ensure the identical mass distribution. Therefore, the structural mass of the body components to be replaced and their cumulative centre of gravity (CoG) have to be determined. This input can be obtained by the preprocessor element output data. The components of the centre of gravity and the representative substitute mass of the replaced structure can be seen in table 2 . In addition, the centre of gravity of the connecting points of the rear axle has to be determined. In the simplified vehicle model, these points serve as a connecting point for a beam element, which prevents rotational distortion of the vehicle structure and the beams for the structural stiffness during crash.

Table 2: Calculated centre of gravity and structural mass of replaced vehicle structure

\begin{tabular}{lcc}
\hline & replaced vehicle structure & rear axle \\
\hline Centre of gravity; $x$ coordinate & $-2630.60 \mathrm{~mm}$ & $-3102.52 \mathrm{~mm}$ \\
\hline Centre of gravity; y coordinate & $-1.12 \mathrm{~mm}$ & $12.91 \mathrm{~mm}$ \\
\hline Centre of gravity; z coordinate & $573.46 \mathrm{~mm}$ & $445.97 \mathrm{~mm}$ \\
\hline Representative structural mass & $720.2 \mathrm{~kg}$ & $73 \mathrm{~kg}$ \\
\hline
\end{tabular}

\section{Determination of Stiffness of the Replaced Vehicle Structure}

As described above, in addition to the load paths, the simplified vehicle model takes into account the stiffness of the body structure to be replaced. The longitudinal stiffness is determined, as shown in figure 14, by an explicit structural simulation which takes the influence of joints, rubber bearings as well as interior into account. The full vehicle is cut at the interface and the CoG of the rear axle act as 
a bearing point. A rigid body element at the interface is used for load introduction; table 3 shows the resulting displacement at the interface at an applied force of $1000 \mathrm{~N}$. This results in a longitudinal stiffness of $23584.9 \mathrm{~N} / \mathrm{mm}$ for the investigated car model.

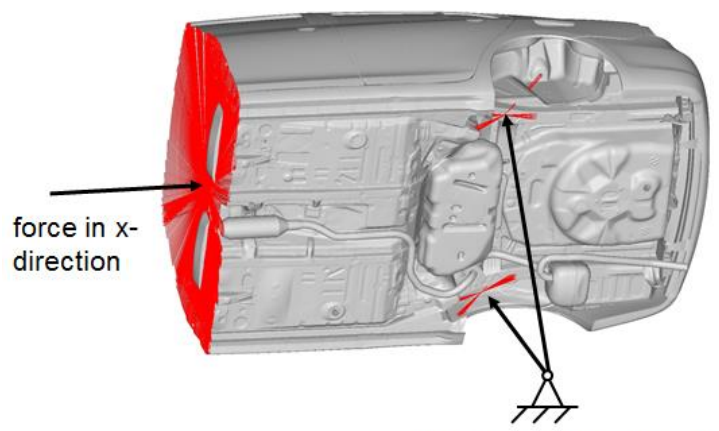

Table 3: Calculated longitudinal stiffness of replaced vehicle structure

connection points rear axle

\begin{tabular}{cc}
\hline force $_{\mathrm{x}}$ & $1000 \mathrm{~N}$ \\
\hline displacement $_{\mathrm{x}}$ & $0.0424 \mathrm{~mm}$ \\
\hline stiffness $_{\mathrm{x}}$ & $23584.9 \mathrm{~N} / \mathrm{mm}$ \\
\hline
\end{tabular}

Fig. 14: FEM model to determine the longitudinal stiffness of a replaced vehicle structure

\section{Modelling with Springs, Dampers and a Discrete Beam for Stiffness of the Truncated Structure}

All previously determined parameters are finally used in the modelling of the simplified vehicle model. The final description of the simplified crash model is shown in figure 15 . The model consists of the FE - model of the front car structures up to the interface, beams for the structural stiffness representations, a mass element at the centre of gravity of the car rear structure and one additional node exactly between the two attachment points of the rear axle. On this node an additional beam element is attached to avoid rotational distortion of the surrogate model during crash. The second attachment point of the beam element is the centre of gravity of the interface.

Between this attachment node and the centre of gravity of the interface, an additional beam element is positioned to represent the influence of the rear suspension on the crash behavior, which influence and stabilize the rotational motion of the car during crash.

The load path distribution at the interface is obtained due to the different stiffness representations of the beam elements. For each assembly one spring- damper element is positioned with a structural stiffness according to the percentual impulse distribution, which was obtained in the model generation steps 1 to 3 . For the investigated car, the impulse distribution is shown in figure 12 and the structural longitudinal stiffness of the replaced vehicle structure is listed in table 3.

For the US NCAP $(100 \%, 56 \mathrm{~km} / \mathrm{h})$ load case, for example, this results in a structural stiffness of $5518.9 \mathrm{~N} / \mathrm{mm}$ for the tunnel structure; corresponding to $23.4 \%$ of the overall stiffness. Through this modelling methodology, the elastic deformation, the kinematic behaviour of the replaced body structure and the load paths in the crash load case are represented by the developed surrogate crash model. 


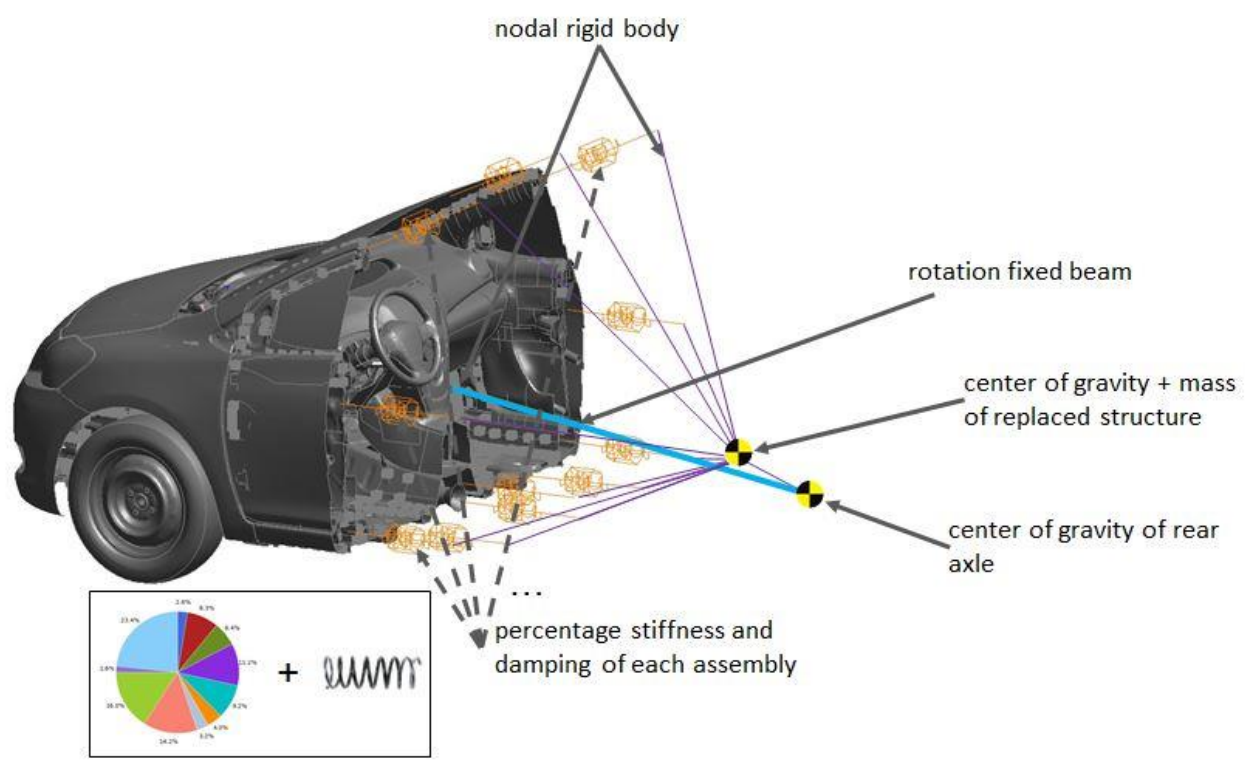

Fig. 15: FEM model of a simplified vehicle crash model with the kinematic numeric representations for the trimmed structures

The load flow from the front structure into the spring-damper elements positioned at the interface is modelled by applying nodal rigid bodies. One particular feature in positioning the spring-damper elements arises from the vectorial orientation of these elements in space. The elements are oriented along profile orientation of the truncated structure to obtain the same load flow in the surrogate model. After the application of the four steps, a simplified crash model is obtained which is able to very efficiently investigate the crash behaviour of the remaining car structures due to the obtained reduction in computational time. The time reduction directly depends on the number of elements remaining in the crash model. Thus, moving the interface toward the front of the car increases the time reduction. However, a position too close to highly deformed structures leads to an additional stiffening of this region. In this case the deviation of the simplified model results will increase.

\section{Verification of the Simplified Offset Deformable Barrier}

As described in section 2.1, the simplified ODB was analysed and verified comparing the compression response of the simplified and the detailed validated ODB shell barrier from LSTC. The simulation of this generic load case showed a good correlation for $100 \%$ and $40 \%$ overlap. For a further verification of the simplified barrier description, additional vehicle crash simulations were performed to also prove the validity of the simplified numerical representation of the barrier for complex intrusion patterns. During a vehicle impact the barrier exhibits different intrusion depths in longitudinal direction as well as over the height which is defined by the shape and the deformation characteristics of the vehicle. For verification, the Euro NCAP $(40 \%, 64 \mathrm{~km} / \mathrm{h})$ crash load case was simulated with the validated Yaris crash model using the simplified and the detailed ODB. The contour output for both simulations is shown in figure 16 . For clarity, the simulation result of the crash model with the detailed barrier is shown in grey, while the simulation output with the simplified barrier is shown in orange. The simulation results show a very good correlation of the structural crash response of the car. While the overall kinematics of the car are represented correctly between the simulations, small differences in folding patterns are obtained in highly deformed structures such as the bonnet and the front spoiler. For a more detailed comparison of the different barrier deformations, figure 17 shows the simplified barrier (orange) overlaid with the detailed barrier (grey) $25 \mathrm{~ms}$ after impact. Additionally, the detailed deformation lines are shown for bumper and main block. The comparison shows that despite the simplified kinematic representation of the barrier, the deformation behaviour can be modelled correctly. However, further verification studies showed that the obtained accuracy of the simplified kinematic representation also depends on the characteristics of the vehicle front. 
The deviation can increase in case of an impact of a vehicle with a flat front end design due to the changed failure characteristics.

The main advantage of the barrier is the reduced number of elements. Since the simplified barrier has only $0.13 \%$ of the elements, the simulation time for a car crash simulation is significantly reduced. Additionally, the simplified barrier allows simulations and optimization studies using coarse vehicle crash models, since the large time step of the simplified barrier will not influence the overall time step of the simulation.

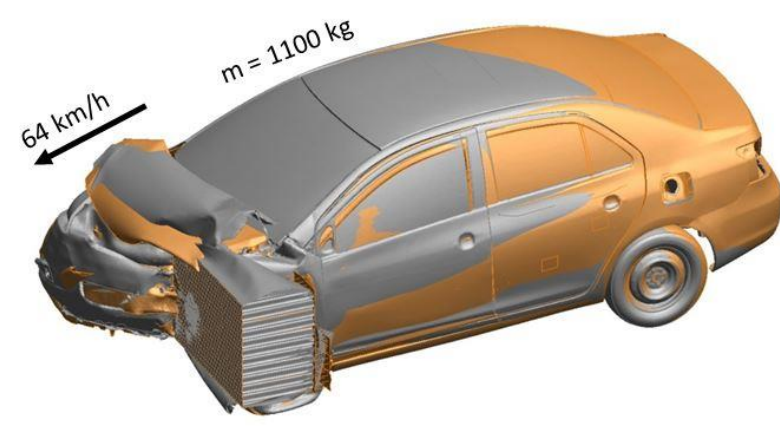

Fig. 16: Comparison of shell barrier and simplified barrier during the Euro NCAP load case ( $40 \%$ offset, $64 \mathrm{~km} / \mathrm{h}$ impact speed)

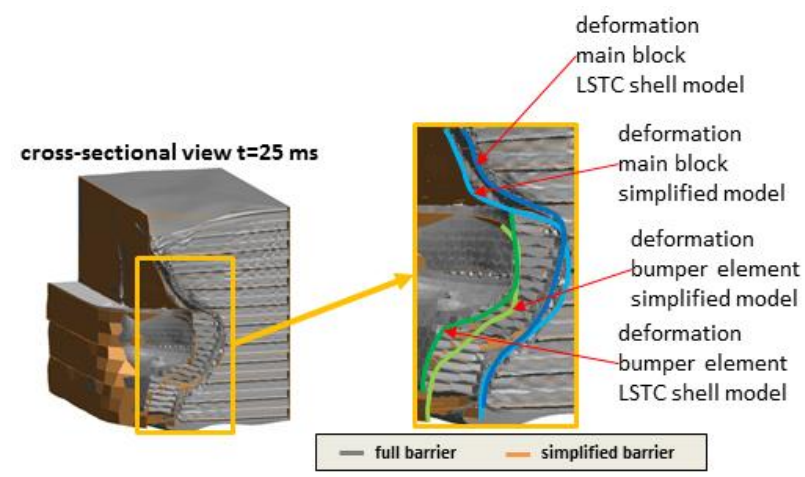

Fig. 17: Comparison of deformation of shell barrier and simplified barrier at $\mathrm{t}=\mathbf{2 5} \mathrm{ms}$ after impact

The energy plot for the two simulations is shown in figure 18. The small deviations between the two barrier representations shows that the simplified barrier model can effectively represent the behaviour of the barrier during the deceleration phase, characterised by an identical rise in internal energy. The small differences, obtained during the rebound phase of the vehicle, are not critical for the structural design process, since they occur after the main structural loading and subsequent deformation of the crash relevant structure.

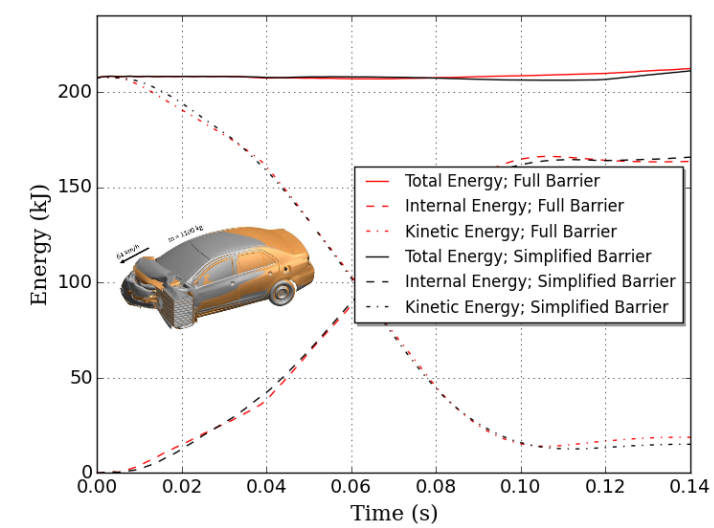

Fig. 18: Comparison of total, kinetic and internal energy for LSTC shell and simplified barrier model at Euro NCAP crash load case $(40 \%$ offset, $64 \mathrm{~km} / \mathrm{h}$ impact speed, vehicle mass $1263 \mathrm{~kg}, 5 \%$ mass scaling)

\section{Verification of the Simplified Vehicle FE Model}

For the verification of the presented methodology for the simplified vehicle crash model generation, crash simulations were carried out investigating the US NCAP $(100 \%, 56 \mathrm{~km} / \mathrm{h})$ crash load case. In this load case the vehicle is driven against a rigid wall at a speed of $56 \mathrm{~km} / \mathrm{h}$. The crash model of the Toyota Yaris was taken, since the available crash model is validated for this crash load case. An additional advantage for this crash scenario is the availability of full vehicle crash test data for validation [22]. The verification is based on different levels; alongside the comparison of the global energies and global deformation pattern, local energy / deformations were also compared. In figure 
19 , the global deformation of the simplified vehicle model [orange] and full vehicle model [grey] is displayed. No major differences can be identified. Besides the same overall crash kinematics between the models, also the same buckling and folding of the bonnet, deformation of the exhaust system and deformation to the chassis is obtained for the two models.

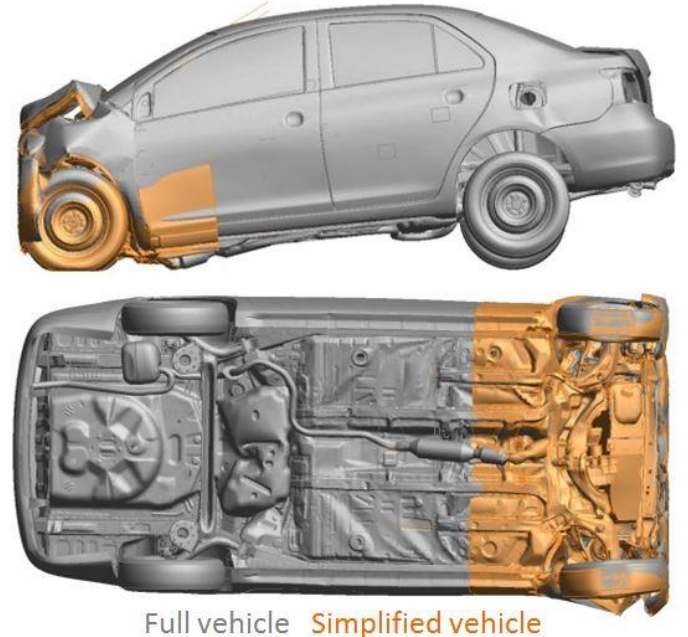

Fig. 19: Comparison of full vehicle and simplified vehicle at US NCAP crash load case $(100 \%$, rigid wall, $56 \mathrm{~km} / \mathrm{h}$ impact speed)

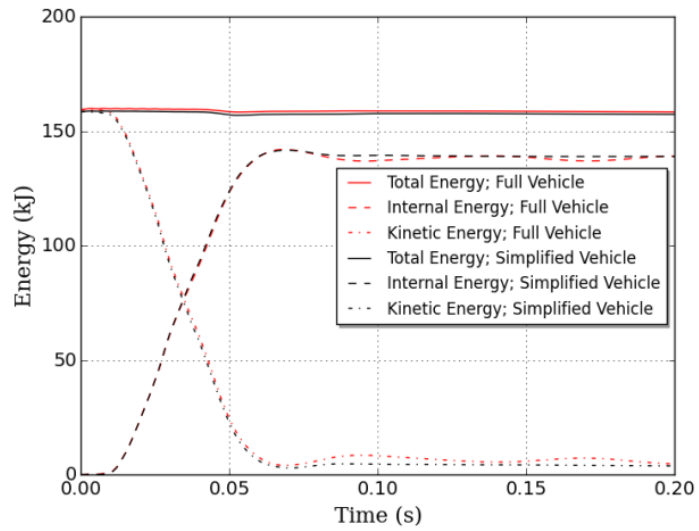

Fig. 20: Comparison of total, kinetic and internal energy for full and simplified vehicle model at US NCAP crash load case $(100 \%$, rigid wall, $56 \mathrm{~km} / \mathrm{h}$ impact speed, vehicle mass $1263 \mathrm{~kg}, 5 \%$ mass scaling)

The energy plot for the two crash simulations is shown in figure 20. The small deviations between the two vehicle representations shows that the simplified vehicle model can effectively represent the crash behaviour of the vehicle during the deceleration phase, characterised by the identical rise in internal energy. Only a small difference can be seen during the rebound phase of the vehicle due to the simplified description of the unloading characteristics of the beam elements in the simplified model representing the stiffness of the different structural assemblies. However, this difference can be seen as unimportant for the structural design process, since it occurs after the main structural loading and subsequent deformation of the crash relevant structure.

An additional important aspect when assessing the behaviour of a structural concept during a crash is the local energy absorption and deformation of individual components or assemblies. A simplified vehicle model must represent these local deformation behaviours during crash with sufficient quality to avoid possible oversizing or even structural failure. If the local energy absorption of the crash box, for example, is overestimated in a simplified vehicle crash model, an insufficient wall thickness can lead to structural failure when up-scaling the results into a full vehicle crash simulation. In figure 21 , the energy absorption characteristics of the crash boxes are shown for both the full vehicle model and the simplified vehicle model. As can be seen from this diagram, the deviation between both models is in the range of approximately $1 \%$, which is sufficient to virtually investigate different crash box designs using the simplified vehicle model.

A further important aspect in the assessment of structural concepts with regard to passenger safety is the intrusion into the passenger compartment. An important structure protecting the survival space of the passenger is the firewall. In figure 22, on the one hand, the deformed firewalls of both models are superimposed; on the other hand, the deviation of the intrusions of both models is depicted in a contour plot. The obtained deviation in the deformation of the firewall shows that the simplified vehicle model can represent the intrusion behaviour correctly, since the deviation between the intrusions is mainly significantly below $5 \%$. Only close to regions of intensive folding of the firewall are slightly higher deviations between the models obtained (approximately 5\%). 


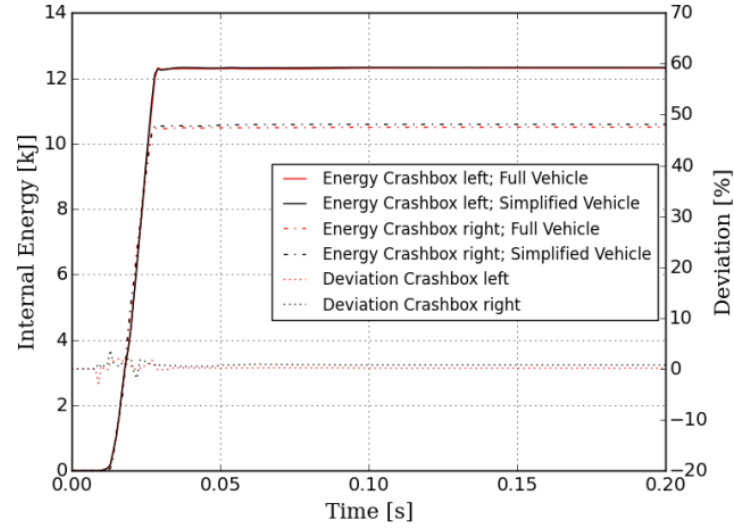

Fig. 21: Comparison of internal energy of the crash boxes for full and simplified vehicle models at US NCAP crash load case $(100 \%$, rigid wall, $56 \mathrm{~km} / \mathrm{h}$ impact speed)

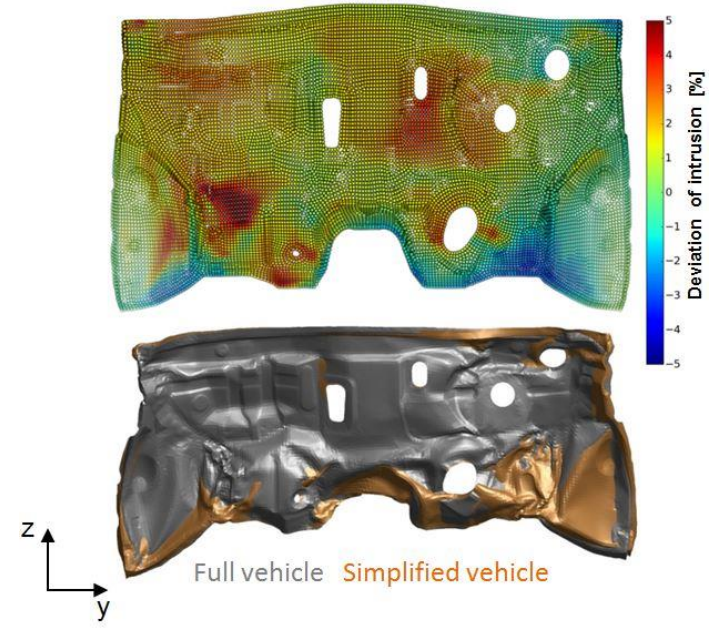

Fig. 22: Comparison of local deformation of the firewall for full and simplified vehicle models at US NCAP crash load case $(100 \%$, rigid wall, $56 \mathrm{~km} / \mathrm{h}$ impact speed)

The published crash test data from [22] were used for the validation of the model simplification methodology. Due to the small quantity of available test data, validation could only be carried out on the global deformation behaviour and the published acceleration curve of a measurement sensor at the top of the engine. The deformation behaviour of the test and simplified vehicle models are depicted in figure 23 . The comparison shows that the simplified vehicle model can predict the global crash behaviour of the vehicle. In figure 24 the acceleration output of the simulation model at the top of the engine is plotted to compare the result with the published test data. The graph shows that the two extreme values of the acceleration curve are represented both qualitatively and quantitatively by the simplified model. It should be mentioned that the obtained deviation is not obtained only by the simplification of the vehicle, since the full crash model also exhibits deviation in the acceleration curve. Since the simplification methodology is based on the global crash models, inaccuracy existing in the global crash model is directly transferred into the simplified vehicle model.

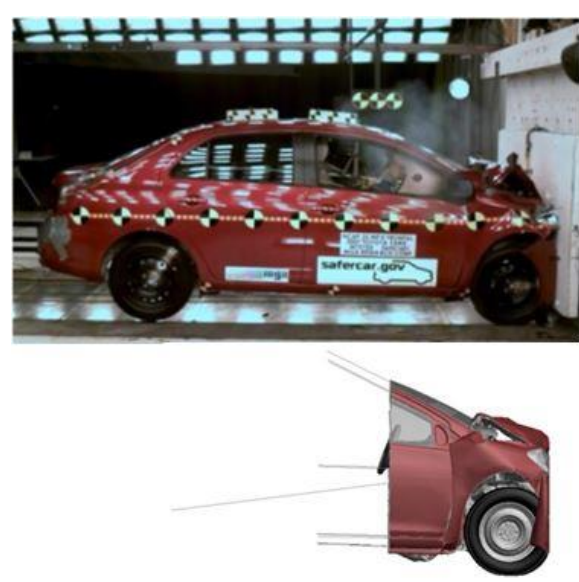

Fig. 23: Comparison of crash behaviour obtained in the full vehicle crash test and in the simulation using the simplified vehicle model (crash test image Toyota Yaris from [28])

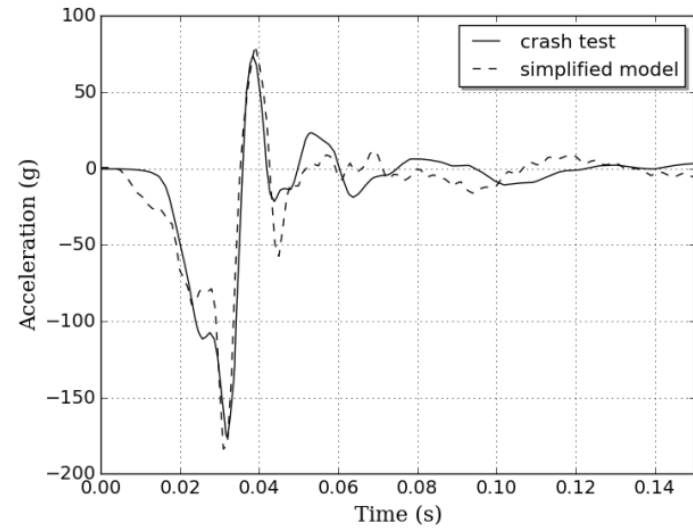

Fig. 24: Comparison of acceleration at the top of the engine in the crash test and for the simplified vehicle model at US NCAP crash load case $(100 \%$, rigid wall, $56 \mathrm{~km} / \mathrm{h}$ impact speed) [28]

\section{Discussion of the Impact on the Computational Time}

A significant challenge in the case of a crash analysis is the high computational time. The main target of simplified crash models is the reduction of computational time with a minimum influence on the simulation results. The presented methodology for generation of surrogate models for deformable barriers and full vehicles provide high-quality results. In this section the effect on the computational time is discussed. For the assessment of the time reduction potentials, all crash simulations were 
performed on the same CASE 2 Cluster on 24 CPUs. The influence of the simplified ODB on the computational time is shown in figure 25 for a full vehicle Euro NCAP offset crash analysis. By comparing the difference in computational time, the impact of the simplified barrier description becomes obvious. The simulation time on the cluster for the detailed crash model is approximately $18 \mathrm{~h}$. This is not practical with regard to validating different derivatives and equipment variants or even for structural optimisation. Through the use of simplified barrier modelling as described in Section 2.1, the computational time for a Euro NCAP crash analysis can be reduced by approximately $77 \%$ to around $4 \mathrm{~h}$. By substituting the detailed ODB by the developed simplified kinematic description of the deformation behavior of the barrier alone, the simulation output can be increased significantly, which allows first small optimisation studies for this crash load case.

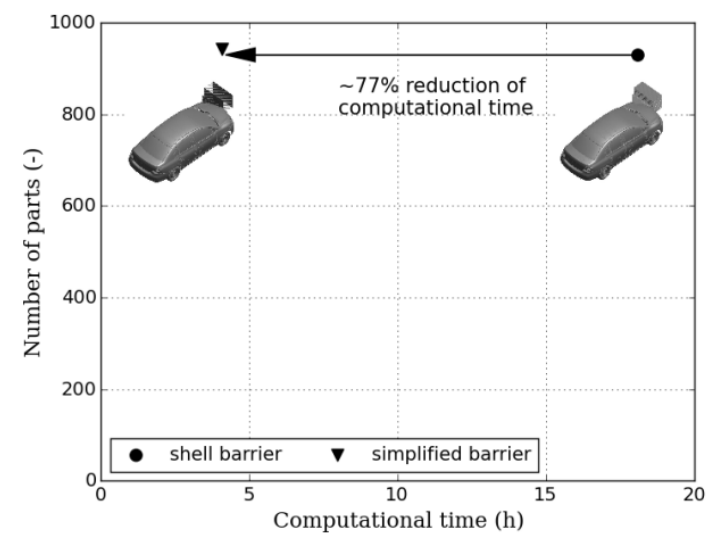

Fig. 25: Reduction of computational time by using simplified barrier description modelling * CASE-2 Cluster 24 CPUs

The identified time reduction potential through the use of kinematic description of the barrier only affects one crash load case. A vehicle has to prove its crashworthiness in a high number of different crash scenarios. Therefore, the reduction through the use of simplified full vehicle modelling is even more important, since the obtained time reduction directly affects many crash load cases independent of the type of impactor. The influence of methodology for the simplified vehicle crash model generation load case is shown in figure 26 on the US NCAP $(100 \%, 56 \mathrm{~km} / \mathrm{h})$. Through the application of the modelling approach, the number of components in the model could be reduced by $50 \%$, and the computational time can be reduced by approximately $65 \%$ to approximately $1.5 \mathrm{~h}$ in this load case. It should be mentioned, that for the simplification approach, this reduction potential depends directly on the chosen interface for model reduction. If an interface is chosen further in the front additional computational time can be saved, but in the same time the correlation between the models will decrease.

The highest impact on the computational time is obtained if both simplified modelling descriptions are combined. This combined effect is shown in figure 27. Through the use of full vehicle modelling alone, the number of components and computational time can be reduced by approximately $50 \%$. Through combined use, the full potential can be exploited. In this way, the computational time can be reduced by approximately $92 \%$ to approximately $1.5 \mathrm{~h}$. This high reduction potential enables resource-efficient computation of various derivatives and structural optimisations in the US NCAP $(100 \%, 56 \mathrm{~km} / \mathrm{h})$ and Euro NCAP $(40 \%, 64 \mathrm{~km} / \mathrm{h})$ load cases. 


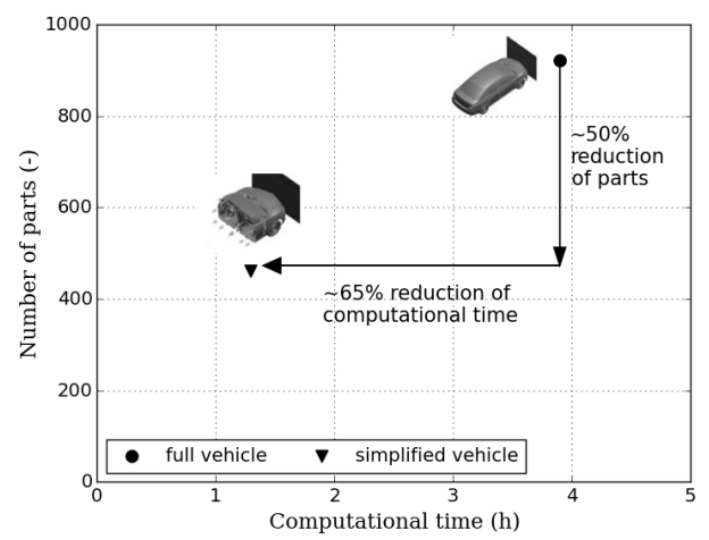

Fig. 26: Reduction of computational time by using a simplified vehicle model at US NCAP crash load case $(100 \%$ overlap, rigid wall, $56 \mathrm{~km} / \mathrm{h}$ impact speed) *CASE-2 Cluster 24 CPUs

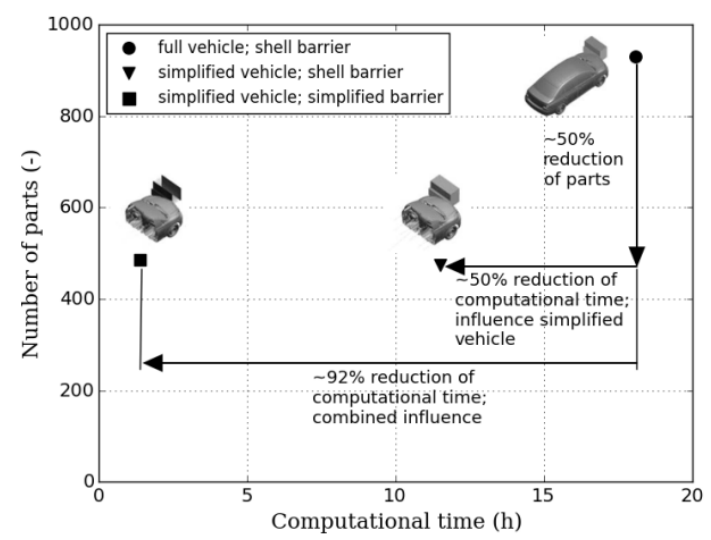

Fig. 27: Reduction of computational time by using a simplified barrier and vehicle model at EURO NCAP load case $(40 \%$ offset, $64 \mathrm{~km} / \mathrm{h}$ impact speed) *CASE-2 Cluster 24 CPUs

\section{Conclusion}

The high computational time is a significant challenge in the computer-aided design and validation of different derivatives and equipment variants or structural optimisation. In this paper, simplified modelling approaches for the Euro NCAP offset barrier and full vehicle models for the US NCAP $(100 \%, 56 \mathrm{~km} / \mathrm{h})$ and Euro NCAP $(40 \%, 64 \mathrm{~km} / \mathrm{h})$ load cases are presented. Using these models, it is possible to significantly reduce the computational time with very little impact on the quality of results. Both approaches distinguish themselves in the fact that characteristics are determined directly from the full model and transferred to the simplified model. The simplified barrier, like the real barrier, consists of two components, the bumper and the main block. Each of these areas is represented by beam elements with the corresponding kinematic characteristics. Due to the deformable representation of the cladding sheet and fine beam discretisation, different degrees of overlap can be modelled over the height as well as over the width of the barrier. Modelling of the barrier has been verified by comparison with the Euro NCAP offset crash load case. Through the use of the simplified barrier modelling, the computational time of a full vehicle crash model can be reduced by approximately $77 \%$.

The presented methodology for simplified vehicle crash model generation also takes into account, in addition to the global stiffness of the replaced structure, the load paths and local stiffness distribution at the interface. Verification of the simplified vehicle model was done by comparing the global energies and global deformation behaviour as well as the local energies and local structural deformations. Quantitative validation was carried out using measurement data from an acceleration signal during a full vehicle test. The simplified vehicle model predicted both extreme values of the acceleration curve in a qualitative and quantitative manner. The simplified vehicle description alone lowered the computational time by approximately $50 \%$ due to the reduced number of elements and parts. Through the combined use of both simplified modelling approaches, the computational time of a Euro NCAP offset crash analysis was reduced by approximately $92 \%$. This time reduction enables resource-efficient computation of various derivatives for the design process. Additionally, structural optimisation studies on crash structures can be performed on simplified global vehicle crash models. This eliminates the risk that applied boundary conditions might affect the optimisation results.

\section{Disclosure statement}

The research leading to these results received funding from the Helmholtz Association of German Research Centres within the research topic Next Generation Car. 


\section{References}

[1] Altair, RADIOSS: Sub-modeling (cut approach), http://www.altairuniversity.com/wpcontent/uploads/2012/08/RADIOSS_CRASH_CUT_V05.pdf, 2012.

[2] Arnaudeau, F., Faster Realistic Crash Simulations, $4^{\text {th }}$ European Hyperworks Technology Conference, Versailles, France, 2010.

[3] Bala, S. and Bhalsod, D., Recent Developments on LSTC Barriers Models, 9. LS-DYNA Forum, Bamberg, 2010.

[4] Beeh, E., Entwicklung einer neuartigen crashadaptiven Vorderwagenstruktur für Fahrzeuge mit alternativen Antriebsvarianten, PhD thesis, German Aerospace Center, ISSN 1434-8454, 2015.

[5] Deb, A. and Srinivas, K. C., Development of a new lumped-parameter model for vehicle sideimpact safety simulation, J. Automobile Engineering, Proc. IMechE, Vol. 222, Part D, 2008, DOI: 10.1243/09544070JAUTO801.

[6] Du Bois, P., Chou, C. C., Fileta, B. B., Khalil, T. B., King, A. I., Mahmood, H. F., Mertz, H. J. and Wismans, J., Vehicle Crashworthiness and occupant protection, American Iron and Steel Institue, Michigan, 2004.

[7] Duddeck, F., Multidisciplinary optimization of car bodies, Struct. Multidisc. Optim. 35 (2008), pp. 375-389, DOI: 10.1007/s00158-007-0130-6.

[8] Duddeck, F. and Wehrle, E., Recent Advances on Surrogate Modelling for Robustness Assessment of Structures with respect to Crashworthiness Requirements, $10^{\text {th }}$ European LS-DYNA Conference 2015, Würzburg, Germany, 2015.

[9] Fender, J., Solution Spaces for Vehicle Crash Design, PhD thesis, Technical University Munich, Chair of Computational Mechanics, Munich, Germany, 2013.

[10] Gandhi, U.N. and Hu, S.J., Data-based approach in modeling automobile crash, Int. J. Impact Engrg. 16(1) (1995), pp. 95-118, DOI: 10.1016/0734-743X(94)E0029-U.

[11] Hilmann, J., On the Development of a Process Chain for Structural Optimization in Vehicle Passive Safety, PhD Thesis, Technical University Berlin, 2009, URN: urn:nbn:de:kobv:83-opus22605.

[12] Jankowski, U., Müller Bechtel, M. and Sans, M., Element Sizes in Crash Calculation, 4. LS-DYNA Anwenderforum, Bamberg, Germany, 2005.

[13] Jonsén, P., Isaksson, E., Sundin, K. G. and Oldenburg, M., Identification of lumped paramter automotive crash models for bumper system development, Int. J. Crashworth. 14(6) (2009), pp. 533-541, DOI: 10.1080/13588260902837262.

[14] Kamal, M. M., Analysis and Simulation of Vehicle to Barrier Impact, SAE Paper No. 700414, 1970.

[15] Kim, H.-S., Kang, S.-Y., Lee, I.-H., Park, S.-H. and Han, D.-C., Vehicle Frontal Crashworthiness Analysis by Simplified Structure Modeling using Nonlinear Spring and Beam Elements, International Journal of Crashworthiness, 2:1, pp. 107-118, DOI: 10.1533/cras.1997.0038.

[16] Kim, C.H., Mijar, A.R. and Arora, J.S., Development of simplified models for design and optimization of automotive structures for crashworthiness, Struct. Multidisc. Optim. 22 (2001), pp. 307-321, DOI: 10.1007/PL00013285.

[17] Klaiber, M.: Einsatz innovativer 3D-Druck-Technologien zur flexiblen Prozessverkettung, 2. Technologietag Hybrider Leichtbau, Stuttgart, Germany, 2015.

[18] Kodiyalam, S., Yang, R.J., Gu, L. and Tho, C.-H., Multidisciplinary design optimization of a vehicle system in a scalable, high performance computing environment, Struct. Multidisc. Optim. 26 (2004), pp. 256-263, DOI: 10.1007/s00158-003-0343-2.

[19] Krinke, S.; Koffler, C.; Deinzer, G. and Heil, U.: Automobiler Leichtbau unter Einbezug des gesamten Lebenszyklus, Springer Verlag, ATZ (06/2010).

[20] Marler, R.T., Kim, C.-H. and Arora, J.S., System identification of simplified crash models using multi-objective optimization, Comput. Methods Appl. Mech. Engrg. 195 (2006), pp. 4383-4395, DOI: 10.1016/j.cma.2005.09.002. 
[21] Mooi, H. G. and Huibers, J.H.A.M., Simple and effective lumped mass models for determining kinetics and dynamics of car-to-car crashes, Int. J. Crashworth. 5(1) (2000), pp.7-23, DOI:

10.1533/cras.2000.0120.

[22] NCAC, Extended Validation of the Finite Element Model for the 2010 Toyota Yaris Passenger Sedan, The George Washington University, 2012.

[23] Pahlavani, M. and Marzbanrad, J., Crashworthiness study of a full vehicle-lumped model using parameters optimisation, Int. J. Crashworth. 20:6, 2015, pp. 573-591, DOI:

10.1080/13588265.2015.1068910.

[24] Pawlus, W., Nielsen, J.E., Karimi, H.R. and Robbersmyr, K.G., Mathematical Modeling and Analysis of a Vehicle Crash, 4th European Computing Conference, Bucharest, 2010, pp. 194-199, ISBN: 978-960-474-178-6.

[25] Qin, Y., A concept to design fleet compatible vehicles for real accident environments, Fortschritt-Bereichte VDI. Reihe 12, Verkehrstechnik/Fahrzeugtechnik, VDI Verlag, Düsseldorf, 2011, ISBN: 3183737124.

[26] Regulation (EC) No 443/2009 of the European Parliament and of the Council of 23 April 2009 setting emission performance standards for new passenger cars as part of the Community's integrated approach to reduce $\mathrm{CO} 2$ emissions from light-duty vehicles.,2009.

[27] Relou, J., Methoden zur Entwicklung crashkompatibler Fahrzeuge, Berichte aus der Fahrzeugtechnik, PhD Thesis, Shaker, Aachen, 2000, ISBN: 382657804X.

[28] Schäffer, M., Münster, M., Sturm, R. and Friedrich, H.E.: Development of an optimised side crash concept for the battery-electric vehicle concept Urban Modular Vehicle, 14. LS-DYNA Forum, Bamberg, 2016.

[29] Schwanitz, P., Sankarasubramanian, H., Werner, S.W., Göhlich, D., Chawla, A. and Mukherjee, S., Methodology for Multiparamter Optimization During the Concept Phase for Crash Relevant Vehicle Structures, 9. Weimar Optimierungs- und Stochastiktage, Weimar, Germany, 2012.

[30] Stein, M., Entwicklung einer Methodik zur Verbesserung der strukturellen Interaktion im PkwPkw-Frontalaufprall, PhD Thesis, Berlin, Germany, 2015.

[31] Tischer, M., Wehrle, E.J. and Baier, H., Reduced modeling of crash barriers for design optimization of space frame automobile strucutres, 13. LS-DYNA Forum, Bamberg, 2014.

[32] Weigert, D., Duddeck, F. and Schluder, H., Automatic Model Reduction by Exploitation of Knowledge from Pre-existing Simulations, 13. LS-DYNA Forum, Bamberg, 2014. 